\title{
ФАКТОРЫ, ВЛИЯЮЩИЕ НА ВЫЖИВАЕМОСТЬ ПАЦИЕНТОВ С САХАРНЫМ ДИАБЕТОМ 2 ТИПА В РЕГИОНАЛЬНОЙ КЛИНИЧЕСКОЙ ПРАКТИКЕ
}

\author{
'Петров А.В., ${ }^{1}$ Стронгин Л.Г., ${ }^{2}$ Тарадайко Н.Ю.
}

'Приволжский исследовательский медицинский университет, Нижний Новгород

2 ГБУз НО «Нижегородская областная клиническая больница им. Н.А. Семашко», Нижний Новгород

ЦЕЛЬ: оценить выживаемость пациентов с сахарным диабетом 2 типа и влияние на нее факторов течения диабета и сопутствующих заболеваний.

МАТЕРИАЛЫ И МЕТОДЫ: в исследование включены 1752 человека с сахарным диабетом 2 типа, обследованных с 2003 по 2017 гг. в рамках клинических исследований кафедры, из них 1403 - работы мобильного диабетологического центра Нижегородской области. Данные о выживаемости получены для 1517 пациентов из регионального регистра сахарного диабета по состоянию на 2018 г. Для оценки влияния на выживаемость использовался регрессионный анализ согласно модели Кокса. Данные в работе приведены в формате $\mathrm{M} \pm \mathrm{SD}$, в квадратных скобках указаны 95\% доверительные интервалы.

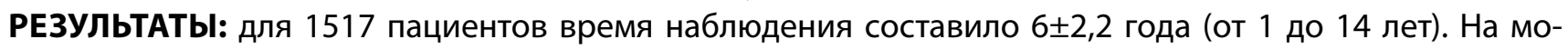

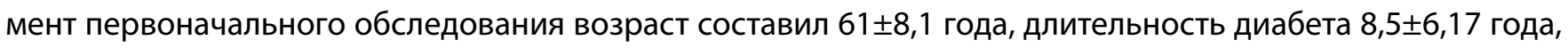

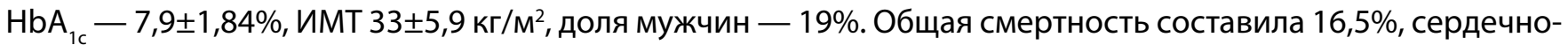

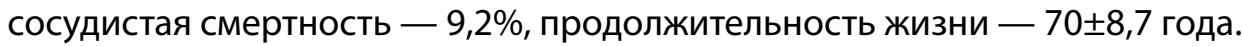

Каждый дополнительный год возраста на момент первичного обследования повышал риск смерти на 7\% (RR 1,07 [1,05-1,09]). Для мужчин риск был выше на 62\% (RR 1,62 [1,2; 2,2]). Наличие ишемической болезни сердца, инфаркта миокарда и острого нарушения мозгового кровообращения в анамнезе приводили к повышению риска сердечно-сосудистой смерти в 1,4 $[1,0 ; 2,0], 3,3[1,8 ; 6,0]$ и 2,7 [1,3; 5,5] раза соответственно.

Увеличение длительности диабета на 1 год было ассоциировано с увеличением риска смерти на 4 [2-6]\%, то есть было сопоставимо с влиянием возраста. Также с каждым дополнительным годом диабета на 5 [3; 7]\% повышался риск сердечно-сосудистой смерти. Ухудшение выживаемости наблюдалось и с ухудшением гликемического контроля - RR 1,12 [1,05; 1,2] для повышения $\mathrm{HbA}_{1 c}$ на $1 \%$ в отношении общей смертности; RR 1,17 [1,08; 1,26] — в отношении сердечно-сосудистой.

Развитие микрососудистых осложнений диабета также было связано с ухудшением выживаемости. Повышение уровня альбуминурии на каждые 10мг/л увеличивало риск на $2[1,5 ; 3] \%$ как для общей, так и сердечно-сосудистой смерти. Увеличение креатинина на 10 мкмоль/л приводило к возрастанию риска смерти от всех причин на $6[1 ; 11] \%$, тогда как повышение риска сердечно-сосудистой смерти было недостоверным - 5 [-2; 12$] \%$. Наличие ретинопатии повышало риск смерти в $1,8[1,4 ; 2,3]$ раза, а сердечно-сосудистой смерти - в $2[1,4 ; 2,8]$ раза.

Улучшение выживаемости отмечалось с повышением приверженности рекомендациям по питанию и физической активности по опроснику SDSCA - снижение риска смерти от всех причин составило 21 [6; 34]\% и 17 [3; 29]\%; сердечно-сосудистой смерти — 22 [2; 38]\% и 27 [12; 40]\%.

Выводы: наряду с традиционными факторами риска, такими как возраст, мужской пол, сердечно-сосудистые заболевания, показано неблагоприятное влияние на выживаемость хронической гипергликемии $\mathrm{HbA}_{1 c^{\prime}}$ продолжительности сахарного диабета, микрососудистых осложнений.

Получены данные о связи приверженности немедикаментозным методам управления диабетом и выживаемости, что может быть обусловлено лучшим контролем заболевания, социоэкономическими условиями, влиянием сопутствующей патологии. Изучение приверженности, эффективности управления сахарным диабетом и воздействующих на них факторов представляется перспективным направлением в улучшении отдаленного прогноза выживаемости пациентов. 